\title{
Color Visual Cryptography with Stacking Order Dependence Using Interference Color
}

\author{
Toshiki Matsuzaki, Huangyi Qin, Kenji Harada \\ Department of Computer Science, Kitami Institute of Technology, Kitami, Japan \\ Email:m1652400113@std.kitami-it.ac.jp
}

How to cite this paper: Matsuzaki, T., Qin, H.Y. and Harad, K. (2017) Color Visual Cryptography with Stacking Order Dependence Using Interference Color. Open Journal of Applied Sciences, 7, 329-336. https://doi.org/10.4236/ojapps.2017.77026

Received: May 24, 2017

Accepted: June 30, 2017

Published: July 3, 2017

Copyright $\odot 2017$ by authors and Scientific Research Publishing Inc. This work is licensed under the Creative Commons Attribution International License (CC BY 4.0).

http://creativecommons.org/licenses/by/4.0/

\begin{abstract}
Visual cryptography is an encryption method that shares a secret image through several encrypted images. General visual cryptography has no stacking order dependence, and only one image can be decoded regardless of stacking order of encrypted images. We previously reported a color visual cryptography using interference color (or polarization color) of retarder films. The interference color changes depending on the stacking order of retarder films. In this paper, we propose and develop a color visual cryptography that displays two images by changing stacking order of retarder films.
\end{abstract}

\section{Keywords}

Visual Cryptography, Polarizer, Interference Color, Birefringent Material

\section{Introduction}

In recent years, various optical encryption methods and devices have been proposed for information security [1]-[7]. Visual cryptography is an encryption method that shares a secret image through several encrypted images. The basic algorithm of visual cryptography was reported by Naor and Shamir [8] and Kafri and Keren [9]. This algorithm is considered to be very effective for encrypting image because it is impossible to estimate or determine the secret image from each separated key image. In conventional visual cryptography, each key image (share) is a random distribution of black-and-white subpixels. By copying shares to transparencies and stacking them, the secret image can be observed.

Many types of visual cryptography have been proposed [8]-[17]. Conventional visual cryptography is based on spatial coding that requires multiple subpixels to modulate light intensity. Therefore, image quality of the decoded image is reduced. This problem is more serious in visual cryptography for color images. Visual cryptography for color images has been reported [13] [14] [15] [16]. A 
color visual cryptography technique is useful for various applications, but more multiple color subpixels are needed. For example, to encryption color images through two shares, each pixel is composed of at least one red, one green, and one blue subpixel. To represent black, the minimum number of subpixels is six, where each pixel is composed of one red, one green, one blue, and three black subpixels [14]. Polarization encoding technique is one of solutions to the reduction of image quality. This encoding technique enables the encryption of each pixel in a secret image into a corresponding single pixel in shares [17] [18]. A visual encryption device using high-order retarder films was also reported by Kowa et al. [17]. These techniques enable the display of only a black-and-white binary image. Improved visual cryptography for gray-level images was reported by Blundo et al. [18]. We previously reported a color visual cryptography using high-order retarder films [19] [20]. This visual cryptography method has no stacking order dependence. A polarization encoding technique with stacking order dependence is reported by Imagawa et al. [21], but the decoded image can only be displayed as a gray-level image. In this paper, we propose a color visual cryptography device with stacking order dependence using interference color of high-order retarder films. Proposed visual cryptography does not reduce image quality of decoded images as the conventional polarization encoding technique. Also, it is possible to display two images in color that has been impossible in conventional polarization encoding technique. We describe the principles of the interference color display with stacking order dependence using polarization films in Section 2. In Section 3, we describe the design of the visual cryptography method with stacking order dependence.

\section{Principles of Interference Color Display with Stacking Order Dependence}

In this section, the principles of interference color displays with stacking order dependence are described. Figure 1 shows the optical composition to for displaying interference color. Figure 1(a) shows a general optical composition for displaying interference color. A retarder film is inserted between two crossed polarizers such that the retarder axis of the retarder film is $45^{\circ}$. Figure 1 (b) shows the calculated interference color chart using CIE standard illumination D65. Various colors can be displayed by changing the retardation $\mathrm{x}$ of the retarder films. Figure 1(c) shows the proposed optical composition for displaying interference color. Three retarder films are inserted between two crossed polarizers such that the retarder axes of the retarder films are $135^{\circ}, 0^{\circ}$, and $45^{\circ}$, respectively. Figures 1 (d)-(g) show the calculated interference color chart using CIE standard illumination D65. Various colors can be displayed by changing the retardation $\mathrm{x}$ of the retarder film, but it also depends on the retardation $\mathrm{y}$. The best retardation y was $140 \mathrm{~nm}$ in this simulation, because various colors can be displayed by changing the retardation $\mathrm{x}$. The calculated interference color shown in Figure 1(d) is almost the same as the interference color of the general optical composition shown in Figure 1(b). We fix the value of retardation y to $140 \mathrm{~nm}$ in our experiment. 


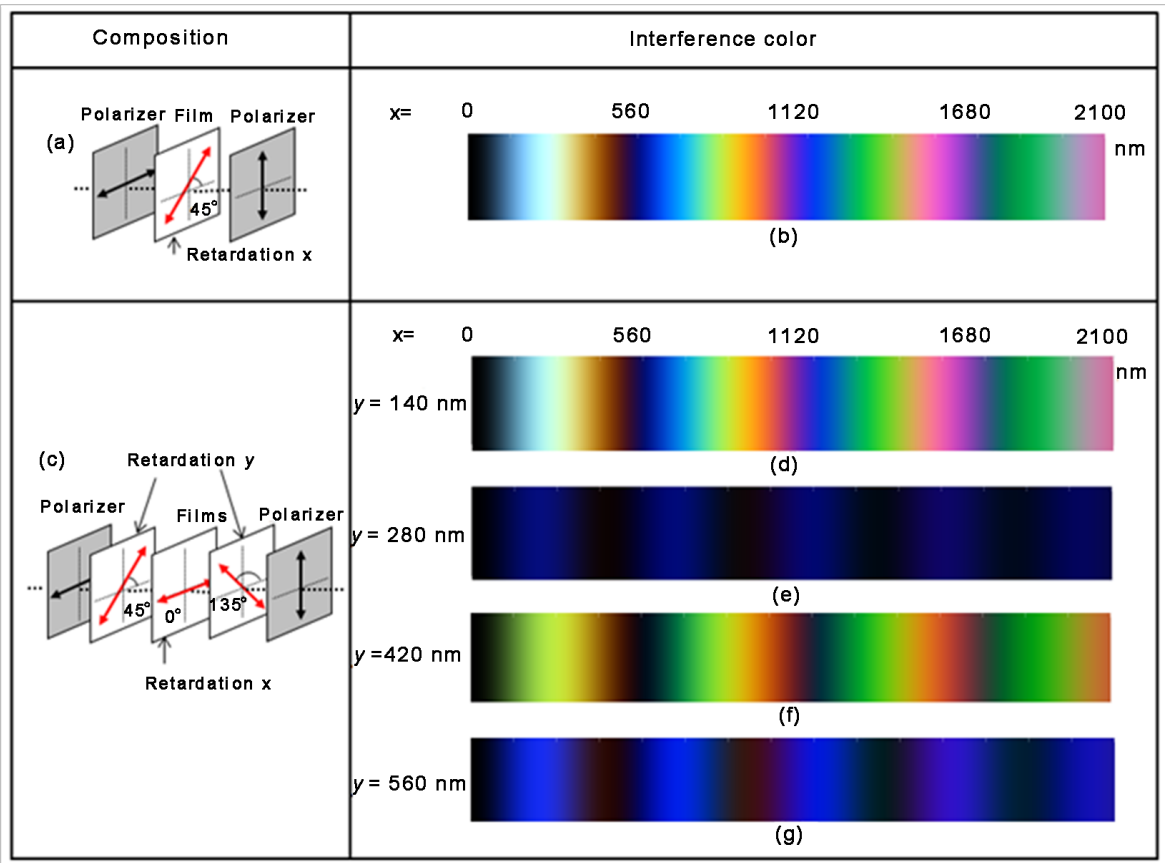

Figure 1. Optical composition and interference color. (a) General optical composition for displaying interference color; (b) Interference color chart of a general optical composition; (c) Proposed optical composition for displaying interference color; (d) Interference color chart of the proposed optical composition when the retardation y is $140 \mathrm{~nm}$; (e) Interference color chart of the proposed optical composition when the retardation y is 280 $\mathrm{nm}$; ( $\mathrm{f}$ ) Interference color chart of the proposed optical composition when the retardation $\mathrm{y}$ is $420 \mathrm{~nm}$; ( $\mathrm{g}$ ) Interference color chart of the proposed optical composition when the retardation y is $560 \mathrm{~nm}$.

Figure 2 shows the composition the of interference color display with stacking order dependence. Four retarder films (films 1, 2, 3, and 4) are inserted between two crossed polarizers such that the retarder axes of the retarder films are $135^{\circ}, 0^{\circ}, 45^{\circ}$, and $0^{\circ}$, respectively. The composition shown in Figure $2(\mathrm{a})$ is almost the same as that shown in Figure 1(c). The only difference is film 4 . The retardation of films 1 and 3 are $140 \mathrm{~nm}$. In this composition, the displayed interference color only depends on the retardation of film 2 . By changing this retardation, the interference color changes as shown in Figure 1(d). No interference color changes by changing the retardation of film 4 . We note that image 1 consists of films 1 and 2, and image 2 consists of films 3 and 4 . By changing the position of images 1 and 2, as shown in Figure 2(b), the displayed interference color changes. In this case, the interference color changes because the retardation of film 4 changes, as shown in Figure 1(d). No interference color changes by changing the retardation of film 2 . To investigate the color variation obtained by this technique, we designed a color model for the polarization images. We used two types of retarder films with retardations of 140 and $560 \mathrm{~nm}$. Conventional $\lambda / 4$ retarder films are used for the $140 \mathrm{~nm}$ retarder films, and conventional $\lambda$ retarder films are used for the $560 \mathrm{~nm}$ retarder films. The wavelength dispersion of the $\lambda / 4$ and $\lambda$ retarder films is the same, and the image size was $100 \times 100 \mathrm{~mm}^{2}$. 


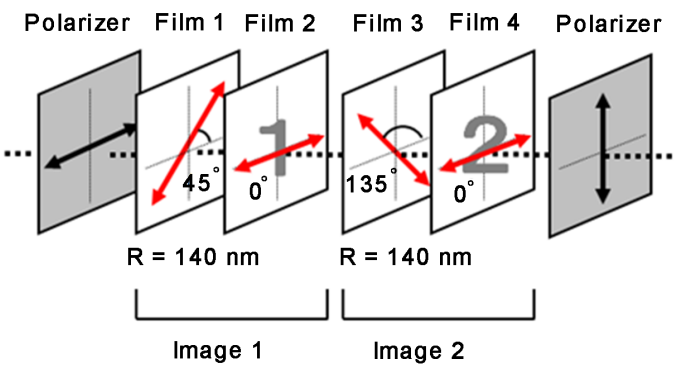

(a)

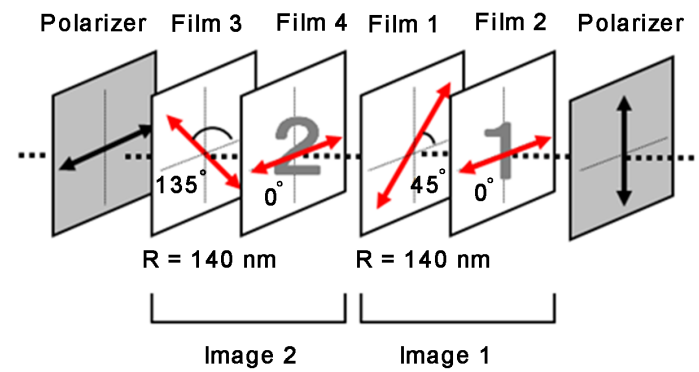

(b)

Figure 2. Composition of the interference color image with stacking order dependence. (a) Image 1 and 2; (b) Image 2 and 1.

Films 1 and 3 were fabricated using a $\lambda / 4$ retarder film. The slow axes of these retarder films are set to $45^{\circ}$, and $135^{\circ}$, respectively. Film 2 and film 4 were fabricated by stacking retarder films. The slow axes of these retarder films were set to $0^{\circ}$ and $90^{\circ}$, respectively. The slow axes of $90^{\circ}$ were used to compensate for the film retardation. The total phase retardations of the colors used in these images are $0,140,280,420,560,840$, and $1260 \mathrm{~nm}$. A white backlight (KLV-7000, Hakuba) was used to view the image. Figure 3(a) and Figure 3(b) show the polarization color image with stacking order dependence.

\section{Design of Visual Cryptography with Stacking Order Dependence}

In this section, we show the proposed method for color visual cryptography with stacking order dependence. In Section 2, we presented the method for designing the interference color image with stacking order dependence. To encrypt the original image, we need to create share images to. Figure 4 shows a simple example of a color visual cryptography algorithm with stacking order dependence. Images 1 and 2 are shared through two shares (shares 1 and 2). Share 1 is composed of three films, (film 2', a retarder film with a retardation of $140 \mathrm{~nm}$, and film 1). Share 2 is composed of three films (film 1', a retarder film with a retardation of $140 \mathrm{~nm}$, and film 2). Various colors can be displayed by changing the phase retardation of the retarder films, and the colors can be changed by adding or subtracting the phase retardations. Image 1 is shared through films 1 and 1 , and image 2 is shared through films 2 and 2'. For the composition shown in 


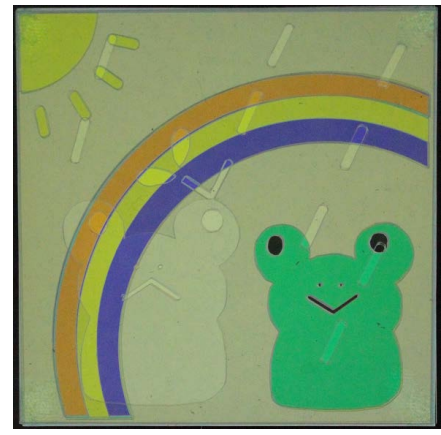

(a)

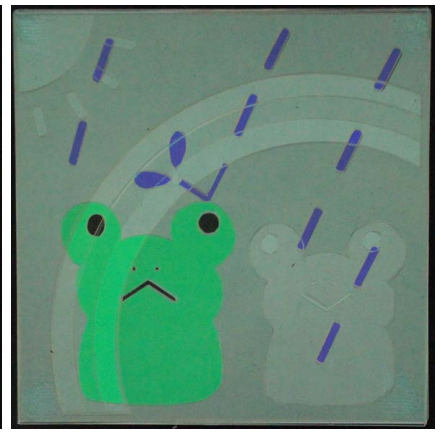

(b)

Figure 3. Polarization color image with stacking order dependence. (a) Image 1 and 2; (b) Image 2 and 1.

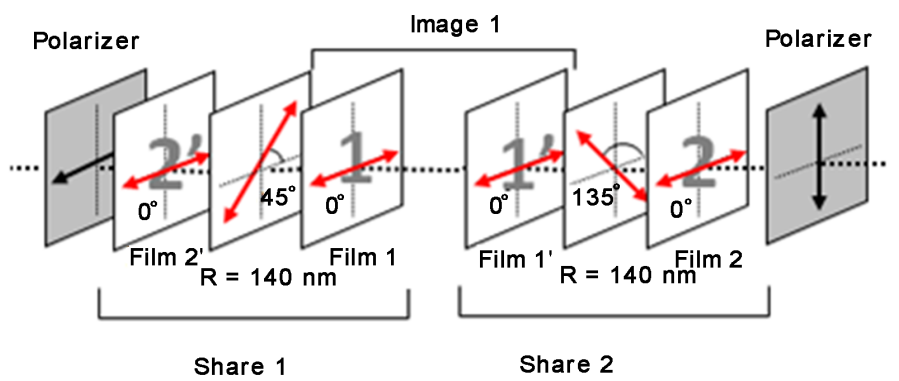

(a)

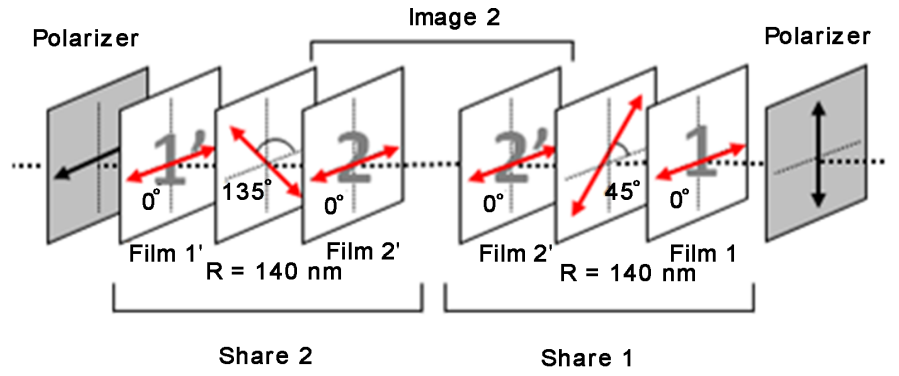

(b)

Figure 4. Composition of the polarization color visual cryptography with stacking order dependence. (a) Share 1 and 2; (b) Share 2 and 1.

Figure 4(a), the interference color changes according to the additional retardation of films 1 and 1', as shown in Figure 1(d). No interference color changes by changing the retardation of films 2 and 2'. By changing the stacking order, as shown in Figure 4(b), the interference color changes according to the additional retardation of films 2 and 2 ' as shown in Figure 1(d). No interference color changes by changing the retardation of films 1 and 1 '.

Next, we designed a prototype of the proposed polarization color visual cryptography with stacking order dependence. Two secret images (images 1 and 2) were composed of 4 -digit numbers. The image sizes were $175 \times 80 \mathrm{~mm}^{2}$. Image 1 is shared through two images, films 1 and 1', and image 2 is shared through two images, films 2 and 2'. Figure 5 shows the phase retardation $(\mathrm{nm})$ and interference color of each film with a crossed polarizer of $\pm 45^{\circ}$. A positive number 

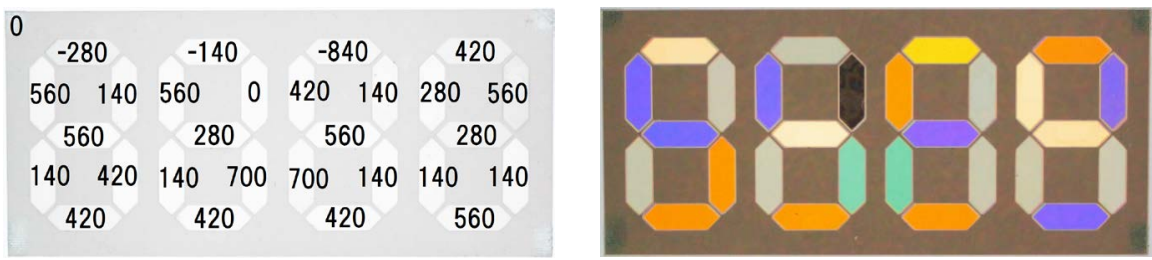

(a)

\begin{tabular}{|c|c|c|c|}
\hline${ }^{-140} 140$ & -420 & 280 & -560 \\
\hline$-700-700$ & $-420-560$ & $-280 \quad 420$ & 280 \\
\hline-420 & 280 & -1120 & 280 \\
\hline $\begin{array}{ll}-280 & 140\end{array}$ & $-700-560$ & $-560-700$ & $-280 \quad 420$ \\
\hline-560 & 140 & 140 & -420 \\
\hline
\end{tabular}

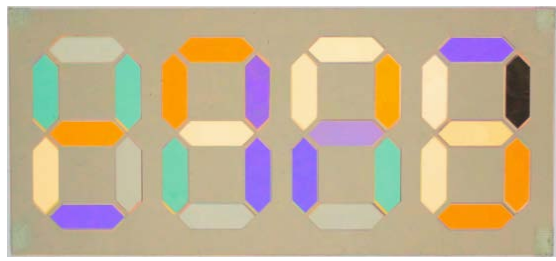

(b)

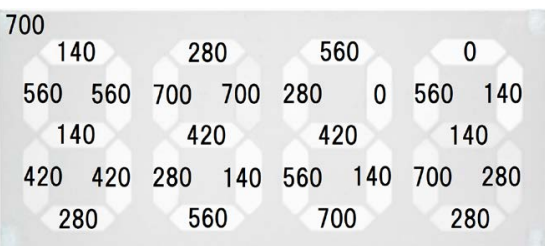

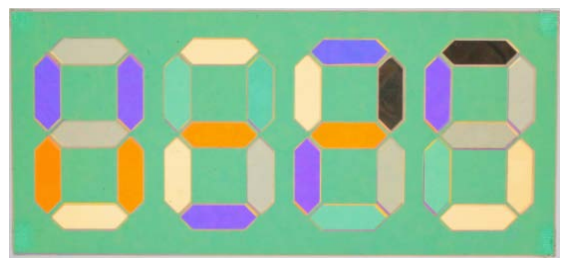

(c)

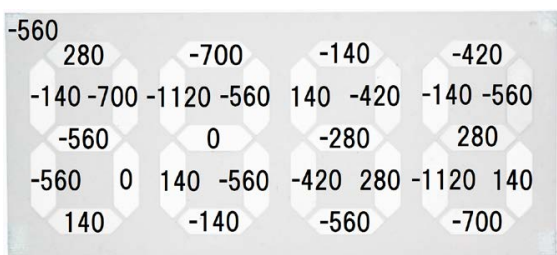

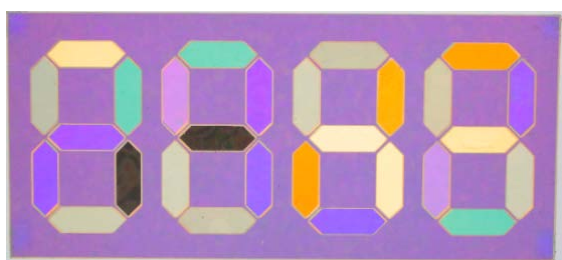

(d)

Figure 5. Model of polarization color visual cryptography with stacking order dependence. (a) Phase retardation and interference color of film 1; (b) Phase retardation and interference color of film 1'; (c) Phase retardation and interference color of film 2; (d) Phase retardation and interference color of film 2'.

indicates that the retarder axis is $0^{\circ}$, and a negative number indicates that the retarder axis is $90^{\circ}$. Four or five retarder films were used to design each film. Even if combinations of interference colors are the same before decoding, different interference colors can be displayed after decoding that depending on axes of retarder films. Also even if combinations of interference colors are the different before decoding, same interference colors can be displayed after decoding. Therefore, it is impossible that decoded images will be leaked from the interference colors of films. Shares 1 and 2, observed with crossed polarizers of $\pm 45^{\circ}$, are shown in Figure 6(a) and Figure 6(b). Share 1 is composed of three films, (film 2', a retarder film with a retardation of $140 \mathrm{~nm}$, and film 1), and share 2 is composed of films (film 1', a retarder film with retardation of $140 \mathrm{~nm}$, and film 2 ). In this case, the secret 4 -digit number is not observed from each share. By stacking shares 1 and 2, as shown in Figure 4(a), the interference color changes according to the additional retardation of films 1 and $1^{\prime}$ as shown in Figure 6(c). The blue secret number "1234" is observed. By changing the stacking order, as 


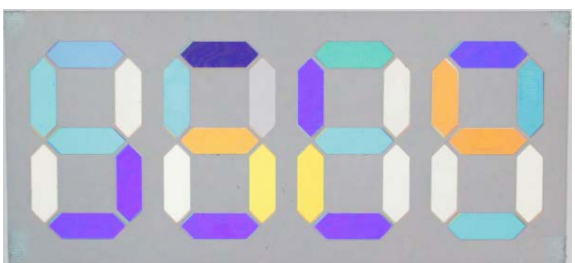

(a)

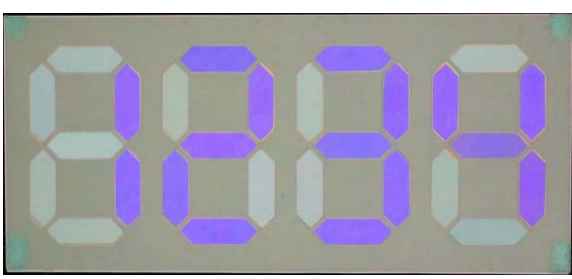

(c)

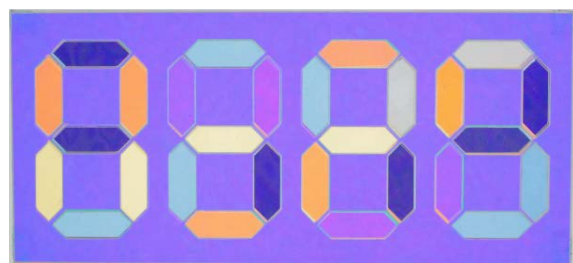

(b)

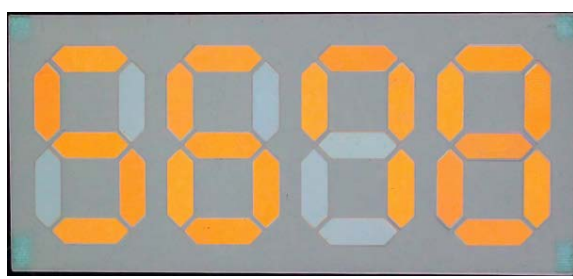

(d)

Figure 6. Polarization color visual cryptography with stacking order dependence. (a) Share 1; (b) Share 2; (c) Decoded image 1; (d) Decoded image 2.

shown in Figure 4(b), the interference color changes because of the additional retardation of films 2 and 2', as shown in Figure 6(d). The orange secret number " 5678 " is observed.

\section{Conclusion}

We produced a color visual encryption technique in which the display image changes depending to the stacking order of encrypted images. We calculated the interference color of the conventional and proposed method. A prototype of a color visual cryptography device with stacking order dependence using interference color was developed. We need no special optical systems to observe portable encrypted images. This technique is very simple and can be applied in security and entertainment.

\section{References}

[1] Fukushima, S., Kurokawa, T. and Sakai, Y. (1991) Image Encipherment Based on Optical Parallel Processing Using Spatial Light Modulators. IEEE Photonics Technology Letters, 3, 1133-1135. https://doi.org/10.1109/68.118031

[2] Javidi, B. and Horner, J.L. (1994) Optical Pattern Recognition for Validation and Security Verification. Optical Engineering, 33, 1752-1756. https://doi.org/10.1117/12.170736

[3] Refregier, P. and Javidi, B. (1995) Optical Image Encryption Based on Input Plane and Fourier Plane Random Encoding. Optics Letters, 20, 767-769.

https://doi.org/10.1364/OL.20.000767

[4] Hayasaki, Y., Matsuba, Y., Nagaoka, A., Yamamoto, H. and Nishida, N. (2004) Hiding an Image with a Light-Scattering Medium and Use of a Contrast-Discrimination Method for Readout. Applied Optics, 43, 1552-1558. https://doi.org/10.1364/AO.43.001552

[5] Sheng, Y., Xin, Z., Alam, M.S., Xi, L. and Li, X.F. (2009) Information Hiding Based on Double Random-Phase Encoding and Public-Key Cryptography. Optics Express, 17, 3270-3284. https://doi.org/10.1364/OE.17.003270 
[6] Javidi, B. and Nomura, T. (2000) Securing Information by Use of Digital Holography. Optics Letters, 25, 28-30. https://doi.org/10.1364/OL.25.000028

[7] Matoba, O. and Javidi, B. (2002) Optical Retrieval of Encrypted Digital Holograms for Secure Real-Time Display. Optics Letters, 27, 321-323.

https://doi.org/10.1364/OL.27.000321

[8] Naor, M. and Shamir, A. (1994) Visual Cryptography. Lecture Notes in Computer Science, 950, 1-12.

[9] Kafri, O. and Keren, E. (1987) Encryption of Pictures and Shapes by Random Grids. Optics Letters, 12, 377-379. https://doi.org/10.1364/OL.12.000377

[10] Shogenji, R. and Ohtsubo, J. (2009) Hiding Information Using a Checkered Pattern. Optical Review, 16, 517-520. https://doi.org/10.1007/s10043-009-0101-9

[11] Machizaud, J., Chavel, P. and Fournel, T. (2011) Fourier-Based Automatic Alignment for Improved Visual Cryptography Schemes. Optics Express, 19, 22709-22722. https://doi.org/10.1364/OE.19.022709

[12] Yamamoto, H., Hayasaki, Y. and Nishida, N. (2003) Securing Information Display by Use of Visual Cryptography. Optics Letters, 28, 1564-1566. https://doi.org/10.1364/OL.28.001564

[13] Yamamoto, H., Hayasaki, Y. and Nishida, N. (2004) Secure Information Display with Limited Viewing Zone by Use of Multi-Color Visual Cryptography. Optics Express, 12, 1258-1270. https://doi.org/10.1364/OPEX.12.001258

[14] Koga, H., Iwamoto, M. and Yamamoto, H. (2001) An Analytic Construction of the Visual Secret Sharing Scheme for Color Images. IEICE Transactions on Fundamentals of Electronics Communications and Computer Sciences, E84-A, 262-272.

[15] Hou, Y.C. (2003) Visual Cryptography for Color Images. Pattern Recognition, 36, 1619-1629. https://doi.org/10.1016/S0031-3203(02)00258-3

[16] Cimato, S., De Prisco, R. and De Santis, A. (2007) Colored Visual Cryptography without Color Darkening. Theoretical Computer Science, 374, 261-276. https://doi.org/10.1016/j.tcs.2007.01.006

[17] Kowa, H., Murana, T., Iwami, K., Umeda, N., Tsukiji, M. and Takayanagi, A. (2011) Development of a Visual Encryption Device Using Higher-Order Birefringence. Proceedings of Society of Photo-Optical Instrumentation Engineers, SPIE, San Diego, p 8.

[18] Blundo, C., De Santis, A. and Naor, M. (2000) Visual Cryptography for Grey Level Images. Information Processing Letters, 75, 255-259.

https://doi.org/10.1016/S0020-0190(00)00108-3

[19] Harada, K., Yamaguchi, T., Tsuchida, T. and Sakai, D. (2013) Visual Cryptography Using Interference Color of High-Order Retarder Films. Japanese Journal of Applied Physics, 52, 6R. https://doi.org/10.7567/JUA.52.062501

[20] Sugawara, S., Harada, K. and Sakai, D. (2013) High-Chroma Visual Cryptography Using Interference Color of High-Order Retarder Films. Optical Review, 22, 544552. https://doi.org/10.1007/s10043-015-0095-4

[21] Imagawa, T., Suyama, S. and Yamamoto, H. (2009) Construction of Visual Cryptography by Use of Polarization-Modulation Films. Japanese Journal of Applied Physics, 48, 9S2. 
Submit or recommend next manuscript to SCIRP and we will provide best service for you:

Accepting pre-submission inquiries through Email, Facebook, LinkedIn, Twitter, etc. A wide selection of journals (inclusive of 9 subjects, more than 200 journals)

Providing 24-hour high-quality service

User-friendly online submission system

Fair and swift peer-review system

Efficient typesetting and proofreading procedure

Display of the result of downloads and visits, as well as the number of cited articles Maximum dissemination of your research work

Submit your manuscript at: http://papersubmission.scirp.org/

Or contact ojapps@scirp.org 